\title{
Psychometric Assessment of the Child Surgery Worries Questionnaire Among Portuguese Children
}

\author{
Sara Fernandes ${ }^{1} \cdot$ Patrícia Arriaga $^{1} \cdot$ Helena Carvalho $^{1} \cdot$ Francisco Esteves $^{2,3}$
}

Published online: 27 July 2017

(C) Springer Science+Business Media, LLC 2017

\begin{abstract}
Worries are common in surgical patients, especially in children. The present study analyzed the factor structure and the psychometric properties of a Portuguese version of the Child Surgery Worries Questionnaire (CSWQ-P) in a Portuguese sample of 490 children. Exploratory factor analysis, conducted via principal axis factoring with oblimin rotation, provided evidence for a four-factor structure of the 21 item questionnaire. A confirmatory factor analysis was also conducted, showing the good fit of this solution. The CSWQ-P proved to have one more subscale than the original Spanish version CSWQ. Correlations with the children's trait anxiety provided evidence of convergent validity for the CSWQ-P. Females also scored higher on worries than males on all subscales. Psychometric properties of this revised version of the CSWQ provided support for use with young children, and indicate the CSWQ-P has value for use in healthcare practice and in clinical research.
\end{abstract}

Keywords Children · Preoperative worries - Exploratory factor analysis - Confirmatory factor analysis .

Measurement invariance $\cdot$ CSWQ

Sara Fernandes

sara_costa_fernandes@iscte.pt

Patrícia Arriaga

patricia.arriaga@iscte.pt

Helena Carvalho

helena.carvalho@iscte.pt

Francisco Esteves

francisco.esteves@iscte.pt

1 Instituto Universitário de Lisboa (ISCTE-IUL), CIS-IUL, Av. das Forças Armadas, 1649-026 Lisbon, Portugal

2 Mid Sweden University, Sundsvall, Sweden

3 CIS-IUL, Lisbon, Portugal

\section{Introduction}

Worries are common phenomena during childhood (Muris, 2007); school-aged children tend to worry about health, safety and injuries (Silverman, Greca, \& Wasserstein, 1995). Hospitalization and surgery also represent a source of stress that can lead to significant levels of anxiety and worry (Kain, Mayes, Weisman, \& Hofstadter, 2000).

Borkovec, Robinson, Pruzinsky, and DePree (1983) defined worry as "a chain of thoughts and images, negatively affect-laden and relatively uncontrollable. The worry process represents an attempt to engage in mental problemsolving on an issue whose outcome is unknown, but contains the possibility of one or more negative outcomes" (Borkovec et al., 1983, p. 10).

Children's worries about surgery tend to be related to death, pain, disability, and negative surgical outcomes (Quiles, Ortigosa, Méndez, \& Pedroche, 1999; Sebastián, Carrillo, \& Quiles, 2001). Children tend to worry about all aspects of a surgical procedure, e.g., efficacy, effects, and duration, but irrational beliefs and distorted perception about anesthesia are often particularly prominent themes in their worries (Rassin, Gutman, \& Silner, 2004; Sebastián et al., 2001).

The number of studies providing information and understanding of children's worries related to hospitalization, surgery, and medical procedures has increased in recent years (Quiles et al., 1999). However, the development and validation of instruments that measure children's worries about surgery and hospitalization still lags behind; only a few of the existing instruments focus on the child's medical and hospital fears, e.g., the Hospital Fear Questionnaire (Roberts, Wurtele, Boone, Ginther, \& Elkins, 1981), the Hospital Fears Rating Scale (Melamed \& Siegel, 1975), and the Children's Medical Hospital Fear Questionnaire 
(Aho \& Erickson, 1985). Data are lacking about the psychometric properties of these three instruments. Additionally, although they assess children's specific fears, they do not assess the cognitive component of worry. For the assessment of worry in children, we highlight the following two self-report questionnaires: the Penn State Worry Questionnaire for Children (PSWQ-C; Chorpita, Tracey, Brown, Collica, \& Barlow, 1997), adapted from The Penn State Worry Questionnaire, which consists of 14 items designed to assess global and common worries in children and adolescents; and the Children Surgery Worries Questionnaire (CSWQ; Quiles et al., 1999) that was developed to assess specific preoperative worries related to surgery, hospital, and medical procedures.

Considering the easy administration of the CSWQ, its clinical utility in pediatric settings, and the acceptable psychometric properties of the original Spanish version (Quiles et al., 1999), we conducted this study to analyze its factor structure in a normative Portuguese sample. Previously, the same authors adapted a child's version of the Surgical Worries Questionnaire (CPCI-N; Quiles, Ortigosa, \& Méndez, 1998) for children aged 7-10 years old, with 17 items and a three-point rating scale. This earlier children's CPCI$\mathrm{N}$ three-point rating scale uses a more restricted response format in comparison to the CSWQ's five-point response scale. According to Chambers and Johnston (2002), for children, reducing the number of points in a response scale format does not reduce the tendency of younger children to respond at the extremes of rating scales. Additionally, these authors suggest that children over 6 years no longer have the tendency to choose the extreme scale scores, and they are able to understand and appropriately use a fivepoint response scale (Chambers \& Johnston, 2002). The present study aimed to validate the Portuguese version of the CSWQ in a younger sample of children using the same 5 -point Likert scale, since it has a wider range of response options compared to a 3-point Likert scale.

Gender differences seem to play an important role in determining children's cognitive responses (Nelson \& Allen, 1999; Sebastián et al., 2001; Silverman et al., 1995). Several studies have shown gender differences concerning worry, indicating a greater tendency among female children to express higher preoperative worries than males (Fernandes, Arriaga, \& Esteves, 2014a; Méndez, Inglés, Hidalgo, García-Fernández, \& Quiles, 2003; Nelson \& Allen, 1999). For this reason, we examined gender differences in children's preoperative worries, and we hypothesized that females would report more worries than males about surgery.

Child's previous experiences are also described in the literature as being related to negative concerns and fears about surgery (Peterson, Ross, \& Tucker, 2002; Watson \& Visram, 2003; Wollin, Plummer, Owen, Hawkins, \&
Materazzo, 2003). Thus, we also analyzed the role of previous surgical experiences in children's worries. Children with past surgery are expected to be more likely to report higher worries than children who never had an operation (Melamed, Dearborn, \& Hermecz, 1983; Peterson et al., 2002; Watson \& Visram, 2003; Wollin et al., 2003).

To summarize, the identification of situations that most worry children regarding hospitalization and surgery might facilitate the design of future intervention programs and prepare children for those events. To address the lack of standardized instruments in clinical practice, the present study aimed to adapt and validate the CSWQ-P among a sample of Portuguese school-age children. This study is also particularly relevant because this is the first instrument in the field developed for preoperative use and validated for a Portuguese population. Moreover, this study was the first to validate the CSQW in a non-Spanish sample. In the present manuscript, to assure clarity, we adopt a unique label for the Portuguese-language version, namely, the CSWQ-P. To our knowledge, no previous study has been conducted to examine the structure of the Spanish-language CSWQ, or CSWQ-P, through a confirmatory factor analysis.

\section{Method}

\section{Participants}

Data were collected from 490 children, in the period from November 2011 through March 2012, in six schools in the Lisbon metropolitan area. Children were not included if they were non-Portuguese speakers or had underlying developmental delays. These exclusion criteria were determined before performing the study. The children's teachers determined if a child met one of the exclusion criteria.

\section{Measures}

\section{Demographic and Clinical Data}

Children's gender, age, level of education, previous hospitalizations, and surgical history were obtained through a short survey (e.g., "have you ever been hospitalized?"; "have you ever had surgery?").

\section{Preoperative Worries}

A Portuguese version (CSWQ-P) of the Child Surgery Worries Questionnaire (CSWQ; Quiles et al., 1999) was used to evaluate children's preoperative worries about surgery, hospitalization, and medical procedures. In the original Spanish-language version, the CSWQ was administered to a sample of 382 Spanish children of 11 through 14 years 
of age. According to the authors, the CSWQ consists of 23 items with three factors that account for $32.95 \%$ of the variance: the first factor, entitled worries about hospitalization (WH) had 11 items and accounted for $13.25 \%$ of the variance; the second factor, worries about medical procedures (WMP) had six items and accounted for $11.29 \%$; and the third factor, worries about the illness and its consequences (WIC) had six items and accounted for 10.29\% of variance (Quiles et al., 1999). Psychometric properties of the original Spanish-language CSWQ suggested good internal consistency and construct validity. The score of item-total correlations ranged from .37 to .66 ; $65 \%$ of the items obtained correlations values higher than .5 with the total CSWQ score; and the Cronbach's alpha coefficient for the global scale was .88 (Quiles et al., 1999). In the present study, the participants were asked to rate each of the 23 items on a scale from $0=$ not at all worried to $4=$ extremely worried. The original CSWQ questionnaire was developed by the original authors in both English and Spanish versions. To develop the Portuguese CSWQ-P, the CSWQ has been independently translated into Portuguese by three psychological researchers, two of whom are co-authors of the present study. The Portuguese translation was then backtranslated to English and to Spanish by two bilingual psychologists in order to crosscheck, as recommended in the literature (Harkness \& van de Vijver, 2011), and it was also revised by some healthcare professionals. In addition, the original CSWQ (fully translated to Portuguese language) has already been used in previous studies in preoperative hospital settings in Portugal (Fernandes \& Arriaga, 2010; Fernandes et al., 2014a; Fernandes, Arriaga, \& Esteves, 2014b).

\section{Trait Anxiety}

Children's trait anxiety was assessed through the StateTrait Anxiety Inventory for Children (STAIC; Spielberger, Edwards, Lushene, Montuori, \& Platzek, 1973). The STAIC was originally developed to assess two dimensions of childhood anxiety: trait and state anxiety (20 items for each scale). While trait anxiety corresponds to a dispositional characteristic, referring to a relatively stable tendency to respond in a certain way to threatening or anxious situations (i.e., the way the individual usually feels and behaves), state anxiety is transitory, reflecting visible reactions to a specific situation with a certain level of intensity (Spielberger, 1983). In the present study we only used the anxiety-trait subscale (STAIC-C2). Each item was answered by the child using a three-point scale $(1=$ never, $2=$ sometimes, $3=$ always $)$, with scores that could range from a minimum of 20 (absence of anxiety) to a maximum of 60 (high level of anxiety state). Typical subscale items are: item 1, "I worry about making mistakes;" and item 17,
"I worry about things that may happen." The Cronbach's alpha coefficient of the original version has shown good internal consistency for both genders, .82 and .87 for male and female samples, respectively (Spielberger et al., 1973). In the Portuguese version (Dias \& Gonçalves, 1999), the STAC-C2 was administered to a sample of 185 children and the analyses have also shown satisfactory internal consistency $(\alpha=.76)$ and adequate convergent validity.

\section{Procedures}

The present study was initially approved by the Portuguese Government Education Department (survey number 0189300001, registered at http://mime.gepe.min-edu.pt/ InqueritoConsultar.aspx?id=2701). Different schools were contacted in the Lisbon metropolitan area. In the schools that officially approved the study, written parental consent was obtained for all children. Children's assent was also obtained. The questionnaires (including the demographic and clinical data survey) were administered in the classroom by the teacher or by the researcher; each child completed the questionnaire individually. The questionnaires took around $15 \mathrm{~min}$ to complete.

\section{Statistical Analysis Plan}

The participants $(N=490)$ were divided into two random subsamples of 244 and 246 participants. The first random half $(n=244)$ was used to conduct an exploratory factor analysis via principal axis factoring (PAF). Oblique rotation was used because several components of preoperative worries were expected to be correlated. The second subsample $(n=246)$ was used in a subsequent confirmatory factor analysis (CFA), performed with the maximum likelihood (ML) method in order to test the construct validity of the identified PAF structure.

First, the multivariate outliers $(n=37)$ were removed from the data set, as recommended in the literature, since their value of Mahalanobis distance exceeded the limits (Burdenski, 2000; Tabachnick \& Fidell, 2007). To evaluate the model fit, multiple fit indices were used: the Chi square and the normed Chi square ( $\chi^{2} / \mathrm{df}$ ratio), with the latter indicating a good fit if below two, as suggested in the literature (Hair, Black, Babin, \& Anderson, 2009; Hoelter, 1983); the Parsimony Comparative Fit Index (PCFI) and the Parsimony Goodness Fit Index (PGFI), for which values should be higher than .60 (Hair et al., 2009). In addition, three indices of incremental close-fit were used (Gignac, 2007): the Normed Fit Index (NFI), the Tucker-Lewis Index (TLI) and the Comparative Fit Index (CFI). According to empirically based cutoff criteria for fit indices (Byrne, 1994; Kline, 1998), CFI, NFI and TLI values below .90 are indicative of a poor fitting model, between .90 and .95 are 
considered marginal but acceptable values, and above .95 are progressively good fitting models. We also analyzed the following two indices of "absolute close-fit:" the root mean square error of approximation (RMSEA) and the standardized root mean residual (SRMR). RMSEA lower or equal to .05 (MacCallum, Browne, \& Sugawara, 1996) and SRMR less than .08 are indicative of a good fit (Hu \& Bentler, 1999).

The measurement invariance was tested to assess whether the factor structure was equivalent across gender, when invariance constraints are added (Cheung \& Rensvold, 2002) and a multigroup confirmatory factor analysis (MGCFA) was used. The model fit differences were analyzed with a Chi square $\left(\Delta \chi^{2}\right)$ test of invariance. Since the Chi square test may not be a reliable indicator of model adequacy, due to its permeability to sample size (Hu \& Bentler, 1998), the $\Delta$ CFI was also used. A value of $\Delta \mathrm{CFI} \leq-.01$ indicates the null hypothesis of invariance should not be rejected (Cheung \& Rensvold, 2002).

Finally, to analyze for potential gender and previous surgical experience differences on preoperative worries, a multivariate analysis of variance (MANOVA) was performed with a 2 (gender: male vs. female) $\times 2$ (previous surgical experience: with vs. without antecedents) betweensubjects factors. All the analyses were carried out using IBM SPSS Statistics 20 and IBM SPSS AMOS 20.

\section{Results}

The total sample consisted of 490 children ( $53.1 \%$ females), aged $7-12$ years $(M=9.22 ; S D=1.52)$, who were enrolled in 2 nd to 7 th grades. Only $35.5 \%$ of children had been previously hospitalized, and $28.0 \%$ had undergone previous surgery. The total data set had only 18 missing values in some item of the CSWQ-P, which were replaced by the mean value.

\section{Descriptive Item Analysis of Preoperative Worries}

Figure 1 displays the Portuguese language version of the questionnaire (CSWQ-P) that was administered to the children in the present study. Table 1 presents the English language equivalent version of these 23 items, which is based on work by the developers of the original CSWQ (Quiles et al., 1998, 1999). The internal consistency for the total score on the 23-item CSWQ-P, which is based on the responses of the total sample of 490 children, was satisfactory (Cronbach's $\alpha=.91$ ).

An initial examination of the 23 items resulted in the removal of item \#6 from subsequent analyses, because most children reported being extremely worried about dying $(86.8 \%)$. This original item was eliminated from further analyses because of a ceiling effect. Table 1 elaborates the worries of the children in the study. In particular, many reported extreme worries related to: pain (item \#4, "being hurt during the operation"-69.0\%, and item \#5, "not being able to bear the pain of the illness"-69.4\%); anesthesia and surgery (item \#12, "waking up during the operation"-69.2\%); surgery's consequences (item \#3, "not being able to do the same things as before"-69.2\%); medical procedures (item \#8, "having to have a needle in my arm for hours" $-60.6 \%$ ); and parental concerns (item \#13, "leaving my parents before the operation"-69.2\%, and item \#23, "my parents being nervous"-68.4\%). These results reveal that worries about surgery and hospitalization are in fact a concern for many children.

\section{Exploratory Factor Analysis, Conducted via Principal Axis Factoring}

A PAF was performed on the first random sample of 244 participants to check the factor structure of the CSWQ-P. The sampling adequacy was confirmed, Kaiser-Meyer-Olkin $=.90 ;$ Bartlett's test of sphericity, $\chi^{2}$ $(210)=2216.250, p<.001$. As shown in Table 2, the following four rotated factors were extracted with eigenvalues above 1 (Kaiser's criterion), accounting for $57.74 \%$ of the total variance: (1) Worries about hospitalization and anesthesia (WHA; 5 items, 10, 11, 16, 18 and 19; $\alpha=.78$ ); (2) Worries about illness and its consequences (WIC; 5 items, 1, 2, 3, 4 and 5; $\alpha=.80$ ); (3) Parental and social worries (PSW; 6 items, 13, 17, 20, 21, 22 and 23; $\alpha=.83$ ); and (4) Worries about medical procedures (WMP; 5 items, 7, 8, 9 , 14 and $15 ; \alpha=.81$ ). The solution with four factors was also validated by scree test (Cattell, 1966) and parallel analysis (Costello \& Osborne, 2005; O’Connor, 2000). Table 2 shows the factor structure of the CSWQ-P, as well as item loadings, communalities, variance explained, eigenvalues and internal consistency for each factor.

Item 12 was eliminated because of lower communality, i.e., the relatively low amount of variance accounted for in that item by the four common factors $\left(h^{2}<.40\right.$; Costello \& Osborne, 2005). Given the exclusion of item 6 because of a ceiling effect, the version of the questionnaire obtained through the PAF analysis consisted of 21 items.

\section{Confirmatory Factor Analysis}

The same four-factor structure of the CSWQ-P obtained from the previous PAF was examined through a confirmatory factor analysis (CFA) on the second random sample composed of 246 participants. Figure 2 displays results for the confirmatory factor analysis of the CSWQ-P. The standardized regression weights ranged from .55 to .80 . The four latent constructs (i.e., the latent factors-WHA, 


\section{Questionário de Preocupações Infantis com a Cirurgia}

INSTRUÇÕES: Em baixo estão escritas várias preocupações que as pessoas podem ter quando estão no hospital para serem operadas. Assinala com uma cruz (X) o grau de preocupação que terias em cada situação, usando a seguinte escala:

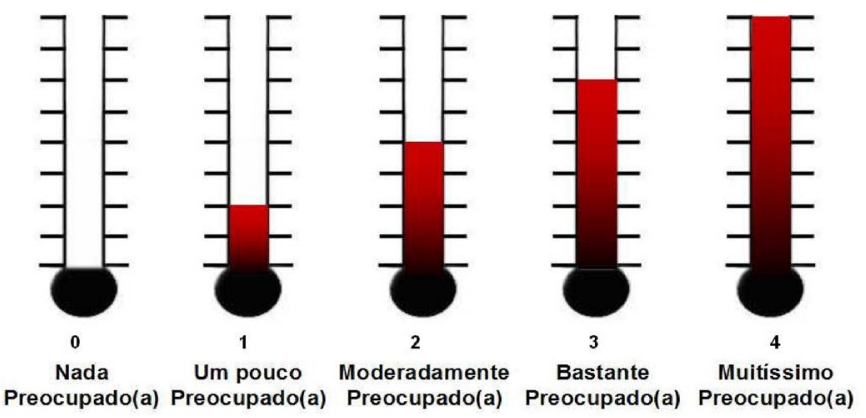

\begin{tabular}{|c|c|c|c|c|c|}
\hline Itens & $\frac{8}{8}$ & 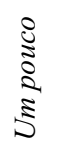 & 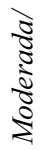 & 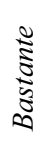 & $\stackrel{\Xi}{\Xi}$ \\
\hline 1. A doença a que me vão operar & 0 & 1 & 2 & 3 & 4 \\
\hline 2. A possibilidade de não recuperar completamente da doença. & 0 & 1 & 2 & 3 & 4 \\
\hline 3. Não ser capaz de fazer as mesmas coisas que fazia antes & 0 & 1 & 2 & 3 & 4 \\
\hline 4. Ser magoado durante a operação & 0 & 1 & 2 & 3 & 4 \\
\hline 5. Não ser capaz de aguentar a dor da doença & 0 & 1 & 2 & 3 & 4 \\
\hline *6. Morrer por causa da doença & 0 & 1 & 2 & 3 & 4 \\
\hline 7. As injecções & 0 & 1 & 2 & 3 & 4 \\
\hline 8. Ter que estar com uma agulha nos meus braços durante horas & 0 & 1 & 2 & 3 & 4 \\
\hline 9. Tirarem-me sangue & 0 & 1 & 2 & 3 & 4 \\
\hline 10. A forma como irão anestesiar-me & 0 & 1 & 2 & 3 & 4 \\
\hline 11. O que sentirei durante a anestesia. & 0 & 1 & 2 & 3 & 4 \\
\hline 13. Deixar os meus pais antes da operação & 0 & 1 & 2 & 3 & 4 \\
\hline 14. O que sentirei durante a operação & 0 & 1 & 2 & 3 & 4 \\
\hline 15. A possibilidade da operação deixar cicatrizes. & 0 & 1 & 2 & 3 & 4 \\
\hline 16. Saber quem está na equipa da operação & 0 & 1 & 2 & 3 & 4 \\
\hline 17. O facto de os meus pais poderem ou não ficar comigo no hospital. & 0 & 1 & 2 & 3 & 4 \\
\hline 18. As actividades que eu poderei fazer enquanto estiver no hospital & 0 & 1 & 2 & 3 & 4 \\
\hline 19. Saber o momento em que poderei sair do hospital & 0 & 1 & 2 & 3 & 4 \\
\hline 20. Mostrar medo ou dor & 0 & 1 & 2 & 3 & 4 \\
\hline 21. A forma como as pessoas do hospital me irão tratar & 0 & 1 & 2 & 3 & 4 \\
\hline 22. Estar com pessoas que eu não conheço & 0 & 1 & 2 & 3 & 4 \\
\hline 23. Os meus pais estarem nervosos. & 0 & 1 & 2 & 3 & 4 \\
\hline
\end{tabular}

$N B$. O item 6 foi eliminado das análises devido ao efeito-tecto, visto preocupar extremamente praticamente todas as crianças.

Fig. 1 Portuguese version of the Child Surgery Worries Questionnaire (CSWQ-P). Figures 1, 2 and Tables 2, 3, and all CSWQ items are reproduced with permission granted by the first author and researcher of the team of Quiles, Ortigosa, and Méndez (Quiles et al.,
1998, 1999) that developed the Spanish-language Child Surgery Worries Questionnaire, and therefore owns the rights to the Portuguese and English versions of the CSWQ 
Table 1 Percentage response rates of the children's preoperative worries

\begin{tabular}{|c|c|c|c|c|c|c|}
\hline \multirow[t]{2}{*}{ CSWQ items } & \multicolumn{2}{|c|}{ Not worried } & \multicolumn{2}{|c|}{ Moderately worried } & \multicolumn{2}{|c|}{$\begin{array}{l}\text { Extremely wor- } \\
\text { ried }\end{array}$} \\
\hline & $n$ & $\%$ & $n$ & $\%$ & $n$ & $\%$ \\
\hline 1. This illness they're going to operate on me for & 72 & 14.7 & 145 & 39.6 & 273 & 55.7 \\
\hline 2. Not recovering fully from the illness & 51 & 10.4 & 75 & 15.3 & 364 & 74.3 \\
\hline 3. Not being able to do the same things as before the illness & 49 & 10.0 & 102 & 20.8 & 339 & 69.2 \\
\hline 4. Being hurt during the operation & 45 & 9.2 & 107 & 21.8 & 338 & 69.0 \\
\hline 5. Not being able to bear the pain of the illness & 48 & 9.8 & 102 & 20.8 & 340 & 69.4 \\
\hline 6. Dying because of the illness & 32 & 6.5 & 33 & 6.7 & 425 & 86.7 \\
\hline 7. Injections & 158 & 32.2 & 144 & 29.4 & 185 & 37.8 \\
\hline 8. Having to have a needle in my arm for hours & 81 & 16.5 & 111 & 22.7 & 297 & 60.6 \\
\hline 9. Them taking blood out of me & 157 & 32.0 & 136 & 27.8 & 197 & 40.2 \\
\hline 10. How they'll anaesthetize me & 119 & 24.3 & 158 & 32.2 & 212 & 43.3 \\
\hline 11. What I'll feel during anesthesia & 109 & 22.2 & 178 & 36.3 & 202 & 41.2 \\
\hline 12. Waking up during the operation & 56 & 11.4 & 93 & 19.0 & 339 & 69.2 \\
\hline 13. Leaving my parents before the operation & 61 & 12.4 & 88 & 18.0 & 339 & 69.2 \\
\hline 14. What I'll feel during the operation & 96 & 19.6 & 125 & 25.5 & 268 & 54.7 \\
\hline 15. The operation leaving scars & 121 & 24.7 & 141 & 28.8 & 224 & 45.7 \\
\hline 16. Knowing who's in the operating team & 166 & 33.9 & 146 & 29.8 & 177 & 36.1 \\
\hline 17. Whether or not my parents can stay with me in hospital & 68 & 13.9 & 96 & 19.6 & 325 & 66.3 \\
\hline 18. What activities I'll be able to do while I'm in hospital & 222 & 45.3 & 146 & 29.8 & 122 & 24.9 \\
\hline 19. Knowing when I'll be able to leave hospital & 154 & 31.4 & 114 & 23.3 & 222 & 45.3 \\
\hline 20. Showing fear or pain & 105 & 21.4 & 147 & 30.0 & 237 & 48.4 \\
\hline 21. The way the hospital staff will treat me & 87 & 17.8 & 138 & 28.2 & 265 & 54.1 \\
\hline 22. Being with people I don't know & 83 & 16.9 & 142 & 29.0 & 265 & 54.1 \\
\hline 23. My parents being nervous & 58 & 11.8 & 97 & 19.8 & 335 & 68.4 \\
\hline
\end{tabular}

Figures 1, 2 and Tables 1,2, and all CSWQ items are reproduced with permission granted by the first author and researcher of the team of Quiles, Ortigosa, and Méndez (Quiles et al., 1998, 1999) that developed the Spanish-language Child Surgery Worries Questionnaire, and therefore owns the rights to the Portuguese and English versions of the CSWQ

WIC, PSW, and WMP) of the CSWQ-P are represented with ellipses, and the 21-measured variables (i.e., 21-items-observed variables) are represented by rectangles. The relationships between the latent constructs and the respective measured variables- the factor loadings-are represented by arrows from the constructs to the items. Each measured variable has an error term that quantifies how much the latent variable does not explain the measured variable.

Several goodness of close-fit indices were examined to obtain a more comprehensive model fit. The model had a $\chi^{2}(176)=302.028, p=.000$ and $\chi^{2} / \mathrm{df}=1.716$. Based on these cut-off criteria, the two measures of absolute close-fit obtained in our study indicated a good-model solution fit $(\mathrm{RMSEA}=.059, p$ [RMSEA $\geq .05]=.102$; SRMR $=.049$ ). As for the incremental close-fit indices, the values obtained ranged from marginal $(\mathrm{NFI}=.878)$ to good standards $(\mathrm{CFI}=.944$; $\mathrm{TLI}=.934 ; \mathrm{PCFI}=.791$; PGFI $=.675)$.

\section{Internal Consistency of the CSWQ Final Version}

The last column of Table 3 presents reliability estimates for the 21-item final version of the CSWQ-P based on the full sample $(N=490)$. Results for the Cronbach's alphas were as follows: for the Global Preoperative Worries score $(\mathrm{GW})$, i.e., for the total CSWQ-P score on the 21-item final version, $\mathrm{GW} \alpha=.91$. For the four factor labels identified in the PAF: WHA (5 items) $\alpha=.74$; WIC (5 items) $\alpha=.79$; PSW ( 6 items) $\alpha=.81$; and WMP (5 items) $\alpha=.79$. Pearson's correlations between the CSWQ-P factors were also calculated based on scores from the total sample $(N=490)$. Correlations among those four CSWQ-P factors ranged from $r=.51$ to .66 . The four CSWQ-P were highly correlated with GW, the global worries score. As shown in the first row of Table 3, values of $r$ ranged from $r=.79$ to .88 . 
Table 2 Factor structure of the Child Surgery Worries Questionnaire (CSWQ-P) using principal factorial analysis after oblique rotation (direct oblimin) in the Portuguese sample

\begin{tabular}{|c|c|c|c|c|c|c|}
\hline \multirow[t]{2}{*}{ Original } & \multirow[t]{2}{*}{ Items } & \multicolumn{5}{|c|}{ Factor structure of the CSQW-P } \\
\hline & & 1. WHA & 2. WIC & 3. PSW & 4. WMP & $h^{2}$ \\
\hline WH & 18. What activities I'll be able to do while I' $m$ in hospital & .586 & -.045 & -.186 & -.059 & .426 \\
\hline WMP & 11. What I'll feel during anesthesia & .582 & .278 & .144 & -.148 & .546 \\
\hline WMP & 10. How they'll anaesthetize me & .437 & .264 & .036 & -.213 & .546 \\
\hline WH & 19. Knowing when I'll be able to leave hospital & .401 & .030 & -.330 & -.007 & .437 \\
\hline WH & 16. Knowing who's in the operating team & .345 & -.035 & -.209 & -.203 & .423 \\
\hline WIC & 2. Not recovering fully from the illness & .035 & .723 & -.112 & .148 & .461 \\
\hline WIC & 3. Not being able to do the same things as before the illness & .081 & .655 & .079 & .003 & .416 \\
\hline WIC & 5. Not being able to bear the pain of the illness & .000 & .512 & -.220 & -.082 & .478 \\
\hline WMP & 4. Being hurt during the operation & -.172 & .459 & -.163 & -.342 & .502 \\
\hline WIC & 1. This illness they're going to operate on me for & .169 & .376 & -.167 & -.124 & .446 \\
\hline WH & 23. My parents being nervous & .039 & .052 & -.750 & .094 & .487 \\
\hline WH & 22. Being with people I don’t know & .051 & .028 & -.582 & -.136 & .498 \\
\hline WH & 17. Whether or not my parents can stay with me in hospital & -.039 & .157 & -.514 & -.089 & .431 \\
\hline WH & 21. The way the hospital staff will treat me & .340 & -.017 & -.489 & -.033 & .495 \\
\hline WH & 13. Leaving my parents before the operation & -.067 & .344 & -.368 & -.232 & .579 \\
\hline WH & 20. Showing fear or pain & .181 & .122 & -.365 & -.186 & .469 \\
\hline WMP & 9. Them taking blood out of me & .072 & -.192 & -.069 & -.785 & .516 \\
\hline WMP & 7. Injections & .107 & .046 & .132 & -.709 & .481 \\
\hline WMP & 8. Having to have a needle in my arm for hours & -.069 & .068 & -.175 & -.641 & .520 \\
\hline WH & 15. The operation leaving scars & .187 & .175 & -.006 & -.416 & .424 \\
\hline \multirow[t]{4}{*}{ WH } & 14. What I'll feel during the operation & .272 & .178 & -.050 & -.331 & .444 \\
\hline & Eigenvalue & 8.115 & 1.601 & 1.324 & 1.084 & \\
\hline & Variance explained & 38.645 & 7.624 & 6.304 & 5.164 & \\
\hline & $\alpha$ & .78 & .80 & .83 & .81 & \\
\hline
\end{tabular}

$N=244 ; h^{2}=$ communality. Letters in the left column indicate the corresponding subscale for each item based on the Spanish original version of the CSWQ: $W H$ worries about hospitalization, WIC worries about illness and its negative consequences, WMP worries about medical procedures; Letters in the top line indicate the corresponding subscale for each item based on the Exploratory Portuguese version: $W H A$ worries about hospitalization and anesthesia, WIC worries about illness and its consequences, PSW parental and social worries, WMP worries about medical procedures

Item 12 was eliminated because of lower communality (<.40). Item 6 was excluded because of a ceiling effect

Table 3 Correlations among four factors of the CSWQ-P, total score $(\mathrm{GW})$ of the CSWQ-P and the Trait-Anxiety levels (STAIC-C2); Cronbach alphas for all scales and factors also are shown

\begin{tabular}{lllllll}
\hline & GW & WMP & PSW & WIC & WHA & $\alpha$ \\
\hline GW & - & $.85^{*}$ & $.88^{*}$ & $.79^{*}$ & $.83^{*}$ & .91 \\
WMP & & - & $.62^{*}$ & $.55^{*}$ & $.66^{*}$ & .79 \\
PSW & & - & $.64^{*}$ & $.64^{*}$ & .81 \\
WIC & & & - & $.51^{*}$ & .79 \\
WHA & & $.34 *$ & $.44^{*}$ & $.41^{*}$ & $.32^{*}$ & .74 \\
STAIC-C2 & $.45^{*}$ & .36 \\
\hline
\end{tabular}

$G W$ global preoperative worries, WMP worries about medical procedures, WIC worries about illness and consequences, WHA worries about hospitalization and anesthesia, $P S W$ parental and social worries

$* p<.001$

\section{Convergent Validity of the CSWQ Final Version}

Convergent validity was examined by assessing the zeroorder linear correlations between the state anxiety global score (STAIC-C2) and the four CSWQ-P subscales. As expected, Pearson's coefficients were low to moderate, and all statistically significant $(p<.001)$, ranging from $r=.32$ (Worries about hospitalization and anesthesia) to $r=.44$ 


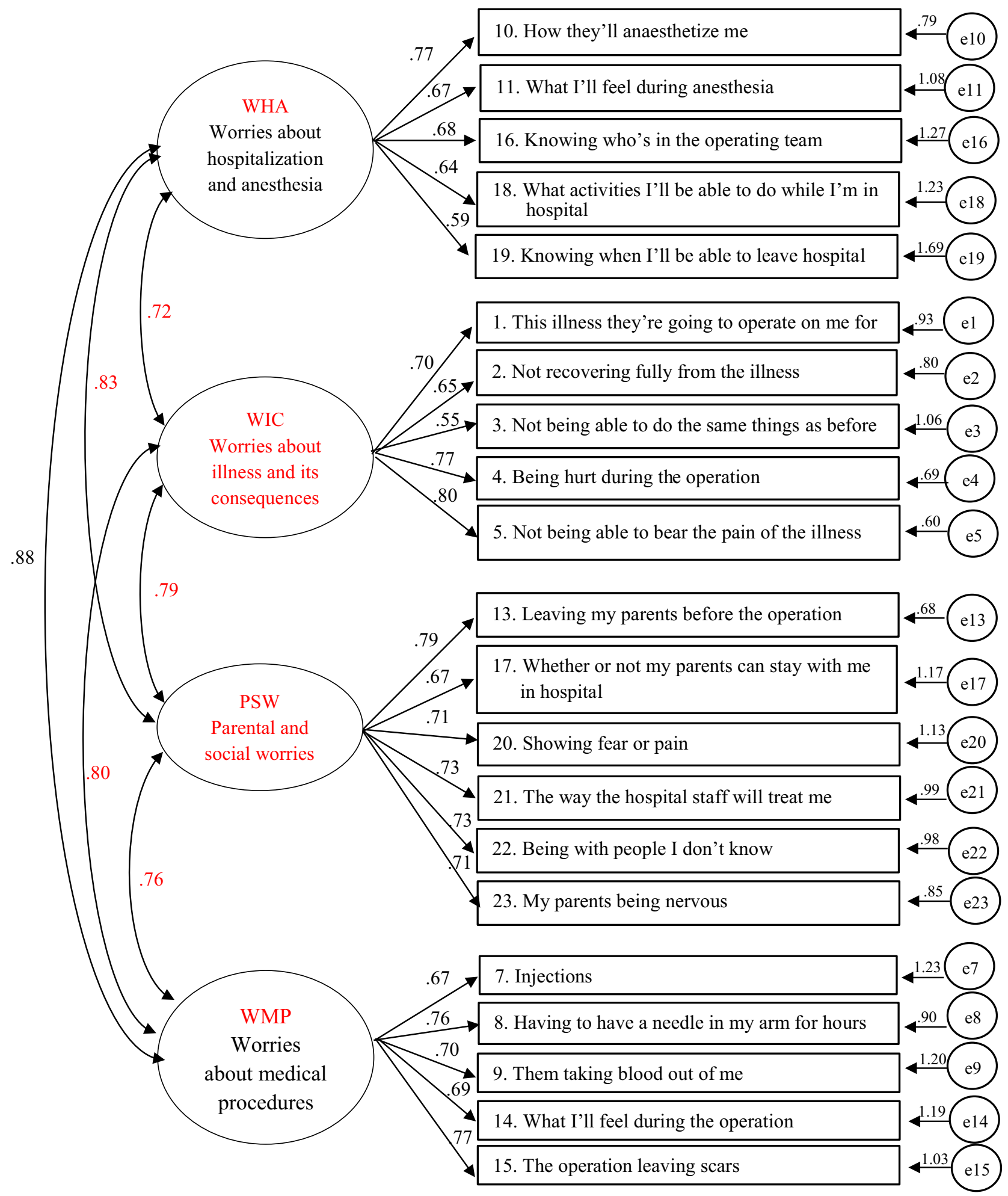

Fig. 2 Confirmatory factorial analysis of the Child Surgery Worries Questionnaire (CSWQ-P) in a Portuguese sample. $N=209$; the regression weights presented were the standardized values: $\chi^{2}(176)=302,028, \quad p<.001 ; \chi^{2} / \mathrm{df}=1.716 ;$ root mean square error of approximation $($ RMSEA $)=.059 ; \quad p \quad[$ RMSEA $\geq .05]=.102$;
SRMR $=.049$; Normed Fit Index $(\mathrm{NFI})=.878$; Comparative Fit Index $(\mathrm{CFI})=.944$; Tucker-Lewis Index $(\mathrm{TLI})=.934$; Parsimony Comparative Fit Index $(\mathrm{PCFI})=.791$; Parsimony Goodness Fit Index $(\mathrm{PGFI})=.675$ 
(Parental and social worries), indicating that these four scales are related but measure different constructs.

\section{Preoperative Worries as a Function of Children's Gender and Previous Surgical Experiences}

The upper section of Table 4 presents the means and standard deviations of preoperative worries for each of the four subscales, and for the entire sample of 490 children. The middle section of Table 4 presents data separately for males and females; the lower section for children with or without previous surgical experience. Because 54 children were missing data for the independent variables of either gender or previous surgical experience, for subsequent analyses of the effects of these variables, analyses for only 436 children were available.

In order to assess measurement invariance across the gender of the children, two nested models were compared: a baseline model with another model to which was added measurement invariance constraints. A multigroup confirmatory factor analysis yielded a significant Chi square $\left(\Delta \chi^{2}=29.101, p<.001\right)$. Given that the Chi square test is affected by sample size and given that the current sample size was large $(N=490)$, it was essential to analyze the difference between the CFA of the two tested models. Based on the $\triangle$ CFA criterion, measurement invariance was confirmed, $\triangle \mathrm{CFA}=-.002(\mathrm{CFA}=.905$ for the constrained model and CFA $=.907$ for the unconstrained model).

To examine the effects of differences in gender and differences in previous surgical experience on preoperative worries, we used a multivariate analysis of variance (MANOVA) with a two (gender: male vs. female) by two (previous surgical experience: with vs. without prior experience) between-subjects design. The choice of conducting a MANOVA was suitable given the moderate correlations between the four factors, $.51<\mathrm{r}<.66, p<.001$.

The multivariate result revealed significant main effects of gender, Wilks' $\lambda=.95, F(4,429)=5.72, p<.001$, $\eta_{p}^{2}=.05$; and previous surgical experiences, Wilks' $\lambda=.98$, $\stackrel{p}{F}(4,429)=2.73, p=.029, \eta_{p}^{2}=.03$. We further examined the univariate $F$ for each preoperative worries factor. As shown in Table 4, female children expressed significantly higher worries compared to male in the following three dimensions of preoperative worries: $F(1,432)=16.50$, $p<.001, \eta_{p}^{2}=.04$, for Worries about illness and its consequences; $F(1,432)=13.65, p<.001, \eta_{p}^{2}=.03$, for Worries about medical procedures; and $F(1,432)=6.39, p=.012$, $\eta_{p}^{2}=.02$, for Parental and social worries. Results also suggested that children with previous surgical experiences reported lower worries about illness and its consequences compared to those without previous antecedents, $F(1$, $432)=5.41, p=.020, \eta_{p}^{2}=.01$. No significant interaction between gender and previous surgical experiences was found, Wilks' $\lambda=.98, F(4,429)=2.21, p=.067, \eta_{p}^{2}=.02$, and the results for the univariate $F$ for each preoperative worries factor did not reveal statistically significant interactions between these two variables in any dimension of preoperative worries (all $p>.05$ ).

\section{Discussion}

The large number of studies reporting children's anxiety and distress caused by surgery show how necessary it is to identify preoperative worries in children. Accurate identification of significant preoperative worries is crucial to facilitate the development of effective and comprehensive preoperative programs to minimize these worries and mitigate the impact of a surgical event. Worry goes beyond a simple preoccupation with an outcome and tends to be related to several affective states (e.g., fear, sadness, anxiety). In addition, it has been considered both a vulnerability factor for clinical symptoms of anxiety and depression, and a central feature in some clinical disorders, such as generalized anxiety disorder (Judah et al., 2013; McEvoy \& Brans, 2013). Although, some authors (Barlow, 2002; Sebastián et al., 2001; Silverman et al., 1995) have defined worry as a cognitive-verbal component of anxiety, recent studies have shown that anxiety and worry are related but independent constructs that should be conceptually distinguished (Kelly, 2004; Zebb \& Beck, 1998). Anxiety is a global construct characterized by somatic sensations, cognitive elements, behavioral components and physical changes (Barlow, 2002; Spielberger, 1983, 2004); other authors have conceptualized worry as cognitive in nature (Borkovec et al., 1983; Zebb \& Beck, 1998).

The present study examined children's preoperative worries and analyzed the factor structure and the psychometric properties of the CSWQ-P in a Portuguese sample. In line with the authors of the original version of the CSWQ, we decided to use a sample recruited from different schools to obtain information about preoperative worries from a normative sample of children. Our findings suggest that death, pain, diseases and their consequences; medical and anesthetic procedures; anticipation of surgical complications; and parental topics are concerns that most worry and frighten children (Quiles et al., 1999; Sebastián et al., 2001).

The original 23-item version of the CSWQ (Quiles et al., 1999) was reduced to 21 items in the present study. In general, as shown in Table 5, the distribution of CSWQ-P items across factors was very similar to that of the original Spanish-language CSWQ. However, in contrast to the original version of the CSWQ, which only had three subscales, for the CSWQ-P, a four-factor solution had a good fit to the 
Table 4 Means and standard deviations on the Four Preoperative Worries Subscales for all children, and as a function of gender and of antecedents of previous surgeries

\begin{tabular}{|c|c|c|c|c|c|c|c|c|c|c|}
\hline & \multicolumn{10}{|c|}{ Children preoperative worries (CSWQ-P) } \\
\hline & \multicolumn{2}{|l|}{ GW } & \multicolumn{2}{|c|}{ WMP } & \multicolumn{2}{|l|}{ PSW } & \multicolumn{2}{|l|}{ WIC } & \multicolumn{2}{|c|}{ WHA } \\
\hline & $M$ & $S D$ & $M$ & $S D$ & $M$ & $S D$ & $M$ & $S D$ & $M$ & $S D$ \\
\hline Total sample $(n=490)$ & 3.37 & .90 & 3.14 & 1.14 & 3.60 & 1.07 & 3.84 & 1.02 & 2.84 & 1.05 \\
\hline \multicolumn{11}{|l|}{ Gender } \\
\hline Male $(n=207)$ & 3.20 & .94 & 2.93 & 1.20 & 3.44 & 1.12 & 3.65 & 1.10 & 2.73 & 1.07 \\
\hline Female $(n=229)$ & 3.52 & .84 & 3.33 & 1.07 & 3.74 & 1.00 & 4.02 & .91 & 2.95 & 1.03 \\
\hline$F$ & \multicolumn{2}{|c|}{$12.50 * * *$} & \multicolumn{2}{|c|}{$13.65 * * *$} & \multicolumn{2}{|l|}{$6.39 *$} & \multicolumn{2}{|l|}{$16.50 * * *$} & \multicolumn{2}{|l|}{2.70} \\
\hline \multicolumn{11}{|l|}{ Previous surgeries } \\
\hline With $(n=137)$ & 3.27 & .98 & 3.15 & 1.23 & 3.49 & 1.12 & 3.66 & 1.14 & 2.74 & 1.13 \\
\hline Without $(n=299)$ & 3.41 & .86 & 3.13 & 1.10 & 3.64 & 1.04 & 3.93 & .95 & 2.89 & 1.02 \\
\hline$F$ & 1.71 & & .12 & & 1.56 & & $5.41 *$ & & 1.71 & \\
\hline
\end{tabular}

$G W$ global worries, WHA worries about hospitalization and anesthesia, WIC worries about illness and its consequences, $P S W$ parental and social worries, $W M P$ worries about medical procedures

$* p<.05, * * p<.01, * * * p<.001$

Table 5 Items distribution and factor structure of the Spanish and Portuguese versions of the Child Surgery Worries Questionnaire

\begin{tabular}{|c|c|c|c|}
\hline Factor & CSWQ original final version & $\begin{array}{l}\text { CSWQ-P Portuguese version (exploratory } \\
\text { analysis) }\end{array}$ & $\begin{array}{l}\text { CSWQ-P Portuguese final version (confirma- } \\
\text { tory analysis) }\end{array}$ \\
\hline 1 & $\begin{array}{l}\text { Worries related to hospitalization } \\
\text { Items: } 13,14,15,16,17,18,19,20,21, \\
22,23\end{array}$ & $\begin{array}{l}\text { Worries about hospitalization and anes- } \\
\text { thesia } \\
\text { Items: } 10,11,16,18,19\end{array}$ & $\begin{array}{l}\text { Worries about hospitalization and anesthesia } \\
\text { Items: } 10,11,16,18,19\end{array}$ \\
\hline 2 & $\begin{array}{l}\text { Worries related to medical procedures } \\
\text { Items: } 4,7,8,9,10,11\end{array}$ & $\begin{array}{l}\text { Worries about medical procedures } \\
\text { Items: } 7,8,9,14,15\end{array}$ & $\begin{array}{l}\text { Worries about medical procedures } \\
\text { Items: } 7,8,9,14,15\end{array}$ \\
\hline 3 & $\begin{array}{l}\text { Worries related to illness and its negative } \\
\text { consequences } \\
\text { Items: } 1,2,3,5,6,12\end{array}$ & $\begin{array}{l}\text { Worries about illness and its consequences } \\
\text { Items: } 1,2,3,4,5\end{array}$ & $\begin{array}{l}\text { Worries about illness and its consequences } \\
\text { Items: } 1,2,3,4,5\end{array}$ \\
\hline 4 & - & $\begin{array}{l}\text { Parental and social worries } \\
\text { Items: } 13,17,20,21,22,23\end{array}$ & $\begin{array}{l}\text { Parental and social worries } \\
\text { Items: } 13,17,20,21,22,23\end{array}$ \\
\hline Total & 23 items & 21 items & 21 items \\
\hline
\end{tabular}

data. The Portuguese version of the questionnaire is composed of four subscales for children's preoperative worries: parental and social; medical procedures; illness and its consequences; and hospitalization and anesthesia.

As expected, all four CSWQ-P subscales were positively and moderately correlated with each other. In addition, they were highly correlated with GW, the total Global Preoperative Worries score. These results also support the use of CSWQ-P as a unidimensional approach to assess children's preoperative global worries. The findings additionally demonstrate the ability of the questionnaire to obtain more specific thematic scores by using a multidimensional approach.

Previous studies have also provided evidence for the convergent validity of measures of childhood worries by relating them to measures of anxiety (Andrews et al., 2010; Brown, Antony, \& Barlow, 1992; Pestle, Chorpita, \& Schiffman, 2008; Rieske et al., 2013). In the present study, the convergent validity of the CSWQ-P was examined by evaluating its correlation with the Portuguese version of the anxiety-trait subscale (STAIC-C2) of the
State-Trait Anxiety Inventory for Children (STAIC; Dias \& Gonçalves, 1999; Spielberger et al., 1973). The correlations between the CSWQ-P and the STAIC-C2 showed convergent validity, providing support for the conceptual relation between worries and anxiety, and suggesting that children with higher levels of trait anxiety may also be more likely to report higher preoperative worries. Future studies should also analyze the convergent validity between the CSWQ-P and other questionnaires that measure stress and fears (Brown et al., 1992; Gloster et al., 2008). It would also be important to differentiate worries from other intrusive cognitive phenomena, such as rumination, since they are closely related processes that can lead to each other or even occur together (McLaughlin, Borkovec, \& Sibrava, 2007; Szabó, 2011). Despite their similarities, worry tends to be more future-oriented while depressive rumination is likely to be more past-oriented (McEvoy \& Brans, 2013). The development of instruments that assess these other varieties of intrusive cognitive phenomena in children with regard to illness, hospitalization and medical procedures 
are also needed. In this manner, because of the lack of selfreport scales related to worry, it would be also interesting to evaluate the discriminant validity of the CSWQ-P with other measures of depressive rumination and among discrete diagnostic categories, such as depression and obsessive-compulsive disorder (Chorpita et al., 1997; Kertz, Lee, \& Björgvinsson, 2014).

In our study, additional analyses were also performed to determine if children's preoperative worries are conditioned by gender and/or previous surgical experiences. We found that female children reported higher preoperative worries than males in all dimensions considered (Quiles et al., 1999; Sebastián et al., 2001). These results are in line with previous studies in the area of childhood worries, showing that female children tend to report more frequent and intense worries than males (Quiles et al., 1999; Sebastián et al., 2001; Silverman et al., 1995). A possible explanation is related to social desirability and cultural patterns of family education (Méndez et al., 2003). Another study demonstrated that females tend to consider future events as more uncertain when compared to males of the same age. The study also suggested that people in ambiguous risk situations may feel more worried due to stronger perceived connections between past situations and the present (Lagattuta, 2007). Furthermore, females also tend to engage in more thought suppression (cognitive avoidance), and report more negative problem orientation, and these two cognitive dimensions (suppression and negative orientation) are usually significant predictors of worry (Robichauda, Dugasa, \& Conwaya, 2003).

We also predicted that children with antecedents of surgery would report higher worry than children who had never been operated on (Melamed et al., 1983; Peterson et al., 2002; Watson \& Visram, 2003; Wollin et al., 2003). However statistically significant differences were only found for specific worries about illness and its consequences. Moreover, contrary to our initial expectations, children with past surgical experience expressed lower worry in this dimension, which could be explained by the concrete, real experience of having survived and mastered a prior situation in which an illness required a surgical intervention. A wide body of literature suggests that previous clinical experiences will affect the negative impact of surgery based on the quality of previous surgical experiences (Moro \& Módolo, 2004). When the previous surgical experience is positive, it may reduce or attenuate the negative preoperative worries (Barros, 1998; Sebastián et al., 2001); but when negative, the previous experience can carry adverse memories, which may negatively exacerbate how a child deals with future medical situations (Kain, Mayes, \& Caramico, 1996; Watson \& Visram, 2003; Wollin et al., 2003). Thus, it would be important for future studies to analyze the quality of previous experiences on children's worries, and distinguish the type of surgery (i.e., outpatient, minor, major, recurrent) they have undergone.

Even though age is an important variable (Quiles et al., 1999; Silverman et al., 1995), it was not examined in the present study because we only included children from 7 to 12 years of age. According to Piaget's theory (as cited in Li \& Lopez, 2008), children at these ages are in the same concrete operational stage of cognitive development, and studies indicate that children's worries tend to be very similar during this stage (Muris, Merckelbach, \& Luijten, 2002; Silverman et al., 1995).

As previously mentioned, the original Spanish-language version of the CSWQ was administered to a sample of children aged between 11 and 14 years. Our findings supported the usefulness and the internal reliability of the CSWQ-P to assess 7-12 year old children's preoperative worries. Future studies should also evaluate the temporal stability of the CSWQ-P version by conducting test-retest reliability with a representative sample. Further, this narrow age range of children limits the generalization of the findings to other age groups; studies with other age populations are recommended. The sample of the present study consisted of a normative sample of children for whom we had no information about the possibility of impending surgery requiring hospitalization and anesthesia, and for whom we had no reason to believe that such surgery was imminent. Our main goal was to gather data on children's general perception about surgery and their main concerns and worries on this matter. Future studies must also validate the CSWQ$\mathrm{P}$ in actual preoperative samples, to examine if the worries reported could be influenced by the specific and subjective situation of each child. Furthermore, it would also be important to study preoperative worries in both normative and clinical samples of children to evaluate the worries and concerns related to the recovery period.

In summary, the results presented in this paper are an important step in the validation of the CSWQ-P for Portuguese children. According to our results, this 21 -item version is a reliable and valid screening measure of preoperative worries in school-aged children. It could be useful in clinical practice, hospital situations and in research with both clinical and nonclinical populations. Also, it can be used to evaluate the effectiveness of preoperative intervention programs. In terms of practical relevance, a timely identification of children's preoperative worries may result in more effective and personalized interventions. Such interventions may enhance children's cooperation because they better understand the surgical event and how to best respond to it. If the children have a better understanding of surgery, this could foster positive attitudes towards preoperative and postoperative healthcare. In sum, this study provides a useful, newly revised version of the CSWQ that is 
still easy to administer and score, and retains the value of the original questionnaire.

Acknowledgements The authors would like to thank the Portuguese Foundation for Science and Technology for providing the financial support for these studies through Ph.D. scholarship grant for the first author (SFRH/BD/61041/2009). The authors acknowledge the availability of teachers and the school committees from Bairro Restelo School, Caselas School, Moinhos do Restelo School, National Conservatory of Dance School, Paula Vincente School and Voz do Operário School. We sincerely thank all children for their participation in this study.

\section{Compliance with Ethical Standards}

Conflict of interest Sara Costa Fernandes, Patricia Arriaga, Helena Carvalho and Francisco Esteves declare that they have no conflict of interest.

Human and Animal Rights All procedures followed were in accordance with the ethical standards of the responsible committee on human experimentation (institutional and national) and with the Helsinki Declaration of 1975 , as revised in 2000

Informed Consent Informed consent was obtained from all individual participants included in the study.

\section{References}

Aho, A., \& Erickson, M. (1985). Effects of grade, gender and hospitalization on children's medical fears. Journal of Developmental and Behavioral Pediatrics, 6, 146-153.

Andrews, G., Hobbs, M., Borkovec, T., Beesdo, K., Craske, M., Heimberg, R., et al. (2010). Generalized worry disorder: A review of DSM-IV generalized anxiety disorder and options for DSM-V. Depression and Anxiety, 27, 134-147. doi:10.1002/ da. 20658.

Barlow, D. (2002). Anxiety and its disorders: The nature and treatment of anxiety and panic (2nd ed.). New York: Guilford Press.

Barros, L. (1998). As consequências psicológicas da hospitalização infantil. [The psychological consequences of hospitalization in childhood]. Análise Psicológica, 1, 11-28.

Borkovec, T., Robinson, E., Pruzinsky, T., \& DePree, J. (1983). Preliminary exploration of worry: Some characteristics and processes. Behaviour Research and Therapy, 23, 481-482. doi:10.1016/0005-7967(83)90121-3.

Brown, T., Antony, M., \& Barlow, D. (1992). Psychometric properties of the Penn State Worry Questionnaire in a clinical anxiety disorders sample. Behaviour Research and Therapy, 30, 33-37.

Burdenski, T. (2000). Evaluating univariate, bivariate, and multivariate normality using graphical and statistical procedures. Multiple Linear Regression Viewpoints, 26, 15-25.

Byrne, B. (1994). Structural equation modeling with EQS and EQS/ Windows. Thousand Oaks, CA: Sage.

Cattell, R. (1966). The scree test for the number of factors. Multivariate Behavioral Research, 1, 245-276.

Chambers, C., \& Johnston, C. (2002). Developmental differences in children's use of rating scales. Journal of Pediatric Psychology, $27,27-36$.

Cheung, G. W., \& Rensvold, R. B. (2002). Evaluating goodness-of-fit indexes for testing measurement invariance. Structural Equation Modeling, 9, 233-255.
Chorpita, B., Tracey, S., Brown, T., Collica, T., \& Barlow, D. (1997). Assessment of worry in children and adolescents: An adaptation of the Penn State Worry Questionnaire. Behaviour Research and Therapy, 35, 569-581.

Costello, A., \& Osborne, J. (2005). Best practices in exploratory factor analysis: Four recommendations for getting the most from your analysis. Practical Assessment, Research \& Evaluation, 10, 1-9.

Dias, P., \& Gonçalves, M. (1999). Avaliação da ansiedade e da depressão em crianças e adolescentes (STAIC-C2, CMAS-R, FSSC-R e CDI): Estudo normativo para a população portuguesa. [Evaluation of anxiety and depression in children and adolescents (STAI-C2, CMAS-R, FSS-R and CDI): A normative study for the Portuguese population]. In A. P. Soares, S. Araújo, \& S. Caires (Eds.), Avaliação psicológica: Formas e contextos [Psychological assessment: Types and contexts] (Vol. VI). APPORT: Braga.

Fernandes, S., \& Arriaga, P. (2010). The effects of clown intervention on worries and emotional responses in children undergoing surgery. Journal of Health Psychology, 15, 405-415. doi:10.1177/1359105309350231.

Fernandes, S., Arriaga, P., \& Esteves, F. (2014a). Providing preoperative information for children undergoing surgery: A randomized study testing different types of educational material to reduce children's preoperative worries. Health Education Research. doi:10.1093/her/cyu066.

Fernandes, S., Arriaga, P., \& Esteves, F. (2014b). Using an educational multimedia application to prepare children for outpatient surgeries. Health Communication, 21, 1-11. doi:10.1080/1041 0236.2014.896446.

Gignac, G. (2007). Partial confirmatory factor analysis: Described and illustrated on the NEO-PI-R. Journal of Personality Assessment, 91, 40-47. doi:10.1080/00223890802484126.

Gloster, A., Rhoades, H., Novy, D., Klotsche, J., Senior, A., Kunik, M., et al. (2008). Psychometric properties of the Depression Anxiety and Stress Scale-21 in older primary care patients. Journal of Affective Disorders, 110, 248-259. doi:10.1016/j. jad.2008.01.023.

Hair, J., Black, W., Babin, B., \& Anderson, R. (2009). Multivariate data analysis (7th ed.). Upper Saddle River, NJ: Pearson Education.

Harkness, J., \& van de Vijver, F. (2011). Developing instruments for cross-cultural research. Manuscript in preparation, cited in Matsumoto, D., \& van de Vijver, F. (2011). Cross-cultural research methods in psychology. Cambridge: Cambridge University Press.

Hoelter, J. (1983). The analysis of covariance structures: Goodness of fit indices. Sociological Methods and Research, 11, 325-344.

Hu, L., \& Bentler, P. M. (1998). Fit indices in covariance structure modeling: Sensitivity to underparameterized model misspecification. Psychological Methods, 3, 424-453.

Hu, L., \& Bentler, P. M. (1999). Cut off criteria for fit indexes in covariance structure analysis: Conventional criteria versus new alternatives. Structural Equation Modeling, 6, 1-55. doi:10.1080/10705519909540118.

Judah, M., Grant, D., Mills, A., Lechner, W., Slish, M., Davidson, C., et al. (2013). The prospective role of depression, anxiety, and worry in stress generation. Journal of Social and Clinical Psychology, 32, 381-399. doi:10.1521/jscp.2013.32.4.381.

Kain, Z., Mayes, L., \& Caramico, L. (1996). Preoperative preparation in children: A cross-sectional study. Journal of Clinical Anesthesia, 8, 508-514.

Kain, Z., Mayes, L., Weisman, S., \& Hofstadter, M. (2000). Social adaptability, cognitive abilities, and other predictors for children's reactions to surgery. Journal of Clinical Anaesthesia, 12, 549-554. doi:10.1016/S0952-8180(00)00214-2. 
Kelly, W. (2004). Examining the relationship between worry and trait anxiety. College Student Journal, Accessed May 16, 2008, from http://www.encyclopedia.com/printable. aspx?id=1G1:123321894.

Kertz, S. J., Lee, J., Björgvinsson, T. (2014). Psychometric properties of abbreviated and ultra-brief versions of the Penn State Worry Questionnaire. Psychological Assessment, 26(4), 1146-1154. doi:10.1037/a0037251.

Kline, R. (1998). Principles and practice of structural equation modeling. New York: Guilford Press.

Lagattuta, K. (2007). Thinking about the future because of the past: Young children's knowledge about the causes of worry and preventative decisions. Child Development, 78, 1492-1509.

Li, H., \& Lopez, V. (2008). Effectiveness and appropriateness of therapeutic play intervention in preparing children for surgery: A randomized controlled trial study. Journal for Specialists in Pediatric Nursing, 13, 63-73. doi:10.1111/j.1744-6155.2008.00138.x.

MacCallum, R., Browne, M., \& Sugawara, H. (1996). Power analysis and determination of sample size for covariance structure modeling. Psychological Methods, 1, 130-149. doi:10.1037/1082-989X.1.2.130.

McEvoy, P., \& Brans, S. (2013). Common versus unique variance across measures of worry and rumination: Predictive utility and mediational models for anxiety and depression. Cognitive Therapy and Research, 37, 183-196. doi:10.1007/ s10608-012-9448-5.

McLaughlin, K., Borkovec, T., \& Sibrava, N. (2007). The effects of worry and rumination on affect states and cognitive activity. Behavior Therapy, 38, 23-38. Doi:10.1016/j.beth.2006.03.003.

Melamed, B., Dearborn, M., \& Hermecz, D. (1983). Necessary considerations for surgery preparation: Age and previous experience. Psychosomatic Medicine, 45, 517-525.

Melamed, B., \& Siegel, L. (1975). Reduction of anxiety in children facing hospitalization and surgery by use of filmed modelling. Journal of Consulting and Clinical Psychology, 43, 511-521. doi:10.1037/h0076896.

Méndez, F. X., Inglés, C. J., Hidalgo, M. D., García-Fernández, J., \& Quiles, M. (2003). Los miedos en la infancia y la adolescencia: un estudio descriptivo. [Fears in childhood and adolescence: A descriptive study]. Revista Electrónica de Motivación y Emoción, 6, 150-163.

Moro, E., \& Módolo, N. (2004). Ansiedade, a criança e os pais. [Anxiety, children and parents]. Revista Brasileira de Anestesiologia, 54, 728-738. doi:10.1590/S0034-70942004000500015.

Muris, P. (2007). Normal and abnormal fear and anxiety in children and adolescents. Oxford: Elsevier Science.

Muris, P., Merckelbach, H., \& Luijten, M. (2002). The connection between cognitive development and specific fears and worries in normal children and children with below-average intellectual abilities: A preliminary study. Behaviour Research and Therapy, 40, 37-56.

Nelson, C., \& Allen, J. (1999). Reduction of healthy children's fears related to hospitalization and medical procedures: The effectiveness of multimedia computer instruction in pediatric psychology. Children's Health Care, 28, 1-13.

O'Connor, B. P. (2000). SPSS and SAS programs for determining the number of components using parallel analysis and Velicer's MAP test. Behavior Research Methods, Instrumentation, and Computers, 32, 396-402.

Pestle, S., Chorpita, B., \& Schiffman, J. (2008). Psychometric properties of the Penn State Worry Questionnaire for children in a large clinical sample. Journal of Clinical Child \& Adolescent Psychology, 37, 465-471.

Peterson, C., Ross, A., \& Tucker, V. C. (2002). Hospital emergency rooms and children's health care attitudes. Journal of Pediatric Psychology, 27, 281-291. doi:10.1093/jpepsy/27.3.281.

Quiles, M., Ortigosa, J., \& Méndez, F. (1998). Cuestionario de Preocupaciones sobre la cirugía infantil: Forma Niños. [Questionnaire of worries about child surgery: Children's Version]. Accessed August 10, 2013, from http://www.um.es/gaihinfa/ publicaciones/p9/p9.htm.

Quiles, M., Ortigosa, J., Méndez, F., \& Pedroche, S. (1999). Cuestionario de preocupaciones sobre cirurgía infantil. [Questionnaire of worries about child surgery]. Psicothema, 11, 601-609.

Rassin, M., Gutman, Y., \& Silner, D. (2004). Developing a computer game to prepare children for surgery. AORN Journal, 80, 10991102. doi:10.1016/S0001-2092(06)60689-3.

Rieske, R., Matson, J., Davis, T. III, Konst, M., Williams, L., \& Whiting, S. (2013). Examination and validation of a measure of anxiety specific to children with autism spectrum disorders. Developmental Neurorehabilitation, 16, 9-16. doi:10.3109/17518423.20 12.705909 .

Roberts, M., Wurtele, S., Boone, R., Ginther, L., \& Elkins, P. (1981). Reduction of medical fears by use of modeling: A preventive application in a general population of children. Journal of Pediatric Psychology, 6, 293-300.

Robichauda, M., Dugasa, M., \& Conwaya, M. (2003). Gender differences in worry and associated cognitive-behavioral variables. Journal of Anxiety Disorders, 17, 501-516.

Sebastián, M., Carrillo F., \& Quiles J. (2001). Preocupaciones prequirúrgicas: Estudio empírico com población infantil y adolescente. [Preoperative worries: Empirical study with children and adolescent populations]. Anales Españoles de Pediatría, 55, 129-134.

Silverman, W., Greca, A., \& Wasserstein, S. (1995). What do children worry about? Worries and their relation to anxiety. Child Development, 66, 671-686. doi:10.1111/j.1467-8624.1995.tb00897.x.

Spielberger, C. (1983). State-trait anxiety inventory: A comprehensive bibliography. Palo Alto, CA: Consulting Psychologists Press.

Spielberger, C. (2004). Encyclopedia of applied psychology. Oxford: Elsevier.

Spielberger, C., Edwards, C., Lushene, R., Montuori, J., \& Platzek, D. (1973). The state-trait anxiety inventory for children (preliminary manual). Palo Alto: Consulting Psychologists Press.

Szabó, M. (2011). The emotional experience associated with worrying: Anxiety, depression or stress? Anxiety, Stress, \& Coping: An International Journal, 24, 91-105. doi:10.1080/10615801003653430.

Tabachnick, B., \& Fidell, L. (2007). Using multivariate statistics (5th ed.). Boston: Allyn and Bacon.

Watson, A., \& Visram, A. (2003). Children's preoperative anxiety and postoperative behaviour. Paediatric Anaesthesia, 13, 188-204. doi:10.1046/j.1460-9592.2003.00848.x.

Wollin, S., Plummer, J., Owen, H., Hawkins, R., \& Materazzo, F. (2003). Predictors of preoperative anxiety in children. Anaesthesia Intensive Care, 31, 69-74.

Zebb, B. J., \& Beck, J. G. (1998). Worry versus anxiety: Is there really a difference? Behavior Modification, 22, 45-61. doi:10.1177/01454455980221003. 